ВАСИЛЕНКО Ирина Алексеевна - доктор политическихнаук, профессор кафедры российской политики факультета политологии Московского государственного университета им. М.В. Ломоносова (119991, Россия, г. Москва, Ломоносовский пр-кт, корп. 4 «Шуваловский»; vasilenko.irina@mail.ru

\title{
«СИНГАПУРСКОЕ ЧУДО» В ФОКУСЕ ПОЛИТИЧЕСКОГО АНАЛИЗА: ИСКУШЕНИЕ И РАЗОЧАРОВАНИЕ В АЗИАТСКОЙ ХАЙ-ТЕК-УТОПИИ
}

Аннотация. В статье анализируется амбициозный проект Сингапура, направленный на строительство "умной нации", использующей «умное управление» и "умные технологии" во всех сферах общественной жизни. Стремительное развитие смарт-технологий в Сингапуре обозначило не только сияющие технологические вершины будущего «умной нации", обещающие материальное изобилие и комфорт, но и не менее опасные гуманитарные и антропологические риски этого проекта, отразившиеся в утрате креативности и гуманности общества. Поэтому переосмысление уникального опыта сингапурского проекта позволит не только лучше осознать его достижения, но также увидеть серьезные проблемы и опасные заблуждения на пути формирования «умной нации».

Ключевые слова: Сингапур, “умная нация», “умный город», смарт-технологии, гуманитарные риски, антропологические риски

$\mathcal{C}_{\mathrm{T}}$ тремительное развитие Сингапура по пути инноваций притягивает внимание и необычайно впечатляет: в течение трех последних десятилетий он превратился из слаборазвитого островного города-государства в одно из самых конкурентоспособных и динамичных государств мира - азиатскую «Кремниевую долину», «умный» город-государство, правительство которого в 2014 г. официально приняло курс на строительство «умной нации». Почему все это стало возможным в такой исторически короткий срок? Каковы опасности и риски сингапурского проекта, опирающегося на интеллектуальные технологии? Останется ли место в этом сверкающем технологическом царстве Добру и Красоте?

В 1960-х гг. Сингапур был бедным городом трущоб, теперь это преуспевающий город первого мира. Интересно, что успехи Сингапура на пути модернизации демонстрируют, насколько незначительна роль территории в этом сложном процессе: государство разбогатело вопреки нехватке земли и природных ресурсов. По мнению известного урбаниста Э. Глейзера, успех Сингапура отражает «поразительную способность плотной агломерации умных людей создавать инновации и преуспевать в том случае, когда их поддерживает весьма компетентный государственный сектор» [Глейзер 2015: 339-340].

Сингапур активно инвестировал в образование, в человеческий капитал. В 1960 г. население острова имело в среднем трехлетнее образование, а уже через четверть века школьники Сингапура стали занимать первые места на международных олимпиадах по математике. Наряду с инвестициями в человеческий капитал внутри страны правительство активно осуществляло политику привлечения иностранных кадров и иностранных инвесторов, понимая, что такая политика потребует строгих правовых норм. В результате сегодня в Сингапуре упрощены регистрация бизнеса, получение налоговых льгот инновационными предприятиями; английский язык в качестве государственного облегчает появление на территории страны международных компаний; разработан стандарт международного класса по созданию инвестиционной инфраструктуры, и Сингапур даже консультирует другие страны по данному вопросу. 
Одновременно здесь установлен жесткий правовой режим, прочно защищена независимость судей.

Сегодня Сингапур располагает прекрасной инфраструктурой, первоклассными портом и аэродромом. В этом городе-государстве высокое качество жизни, которого удалось добиться благодаря реализации высокотехнологичных проектов. Правительство увеличило расходы на образование с 2,8\% до 4,1\%; модернизировало систему начального образования, чтобы готовить школьников к продолжению учебы в технических вузах и колледжах; открыло Национальный технологический институт и учредило Фонд повышения квалификации рабочих, предназначенный для покрытия расходов на эти цели. Так была решена проблема подготовки высококвалифицированных кадров для развития инновационных технологий.

Обратим внимание, что в соответствии со стратегией развития человеческого капитала в Сингапуре инвестиции направляются преимущественно в техническое образование и высокотехнологичные профессии. На гуманитарные направления подготовки кадров средства выделялись по остаточному принципу, в основном на обучение иностранным языкам. Сегодня правительство Сингапура компенсирует до $90 \%$ расходов на обучение своих граждан высокотехнологичным профессиям, а также содействует привлечению первоклассных исследователей из-за рубежа. Сингапур разработал программу Fast Track@ School, чтобы расширить доступ школ к широкополосному Интернету: школы поощряются к работе с промышленными предприятиями для развития и тестирования мультимедийного контента. Подобная практика стала одной из первых в мире ${ }^{1}$. Помимо этого, была разработана серия образовательных программ Got to Be Connected для разных групп населения, в т.ч. для граждан с низкими доходами, для повышения уровня доверия населения к онлайн-услугам и пр. Это позволило Сингапуру сократить имевшийся разрыв между обеспеченными и малообеспеченными семьями в использовании $I T$-технологий. В результате уже в 2006 г. был достигнут 45-процентный уровень охвата населения компьютерной грамотностью в малообеспеченных семьях, что явилось одним из самых высоких показателей в мире и стало фактором ускоренного развития информационных технологий в государстве.

Интересно, что многие аспекты жизни в Сингапуре, включая общественный транспорт и жилье, контролируются государственными компаниями. Около 80\% граждан (все население острова - более 5 млн чел.) живут в государственных квартирах. И хотя в Сингапуре демократия, страной руководит одна партия. Таким образом, контроль над управлением позволяет руководству страны претворять намеченные планы в жизнь достаточно быстро. Например, формирование «умного города» предполагает применение новых технологий во всех сферах экономики, а также активное использование инноваций в государственных проектах.

Отдельного внимания заслуживают внедрение экологически чистых технологий и применение возобновляемых источников энергии. По результатам исследований 2015 г., проведенных подразделением Siemens Green Cities, Сингапур получил самую высокую оценку по развитию экологических технологий среди городов Азии. Так, колоссальные искусственные «деревья» в саду города - это не только знаменитая достопримечательность. Они эффективно поглощают

1 Connected Singapore. A new blueprint for infocomm development. URL: https://www.ida.gov.sg/ / media/Files/About\%20Us/Corporate\%20Publications/Past\%20Infocomm\%20Plans/Connected.pdf (accessed 21.04.2018). 
тепло и аккумулируют дождевую воду, а на вершине каждого из 18 сооружений разместились солнечные батареи, собирающие энергию для освещения сада 1 .

Последовательная реализация перечисленных программ привела к значительным успехам Сингапура в деле внедрения смарт-технологий в городскую инфраструктуру. Это позволило правительству в 2014 г. запустить программу «Умная нация» (Smart Nation), которая стала новым шагом на пути развития «умного города» ${ }^{2}$. Сегодня эта программа активно претворяется в жизнь, но о полной ее реализации говорить еще рано. По заявлениям властей, программа спроектирована для того, чтобы с помощью технологий улучшить качество государственных услуг, наладить связь с гражданами и стимулировать внедрение инноваций в частном секторе. Премьер-министр Сингапура Ли Сянлун в своей речи на Founders Forum Smart Nation Singapore Reception, презентируя программу, подчеркнул: «В Сингапуре различные технологические ноу-хау уже давно интегрированы в государственную инфраструктуру. Например, вы можете создать компанию за 15 минут, полностью через интернет. Можете выбрать школу для своих детей, забронировать спортзал, сделать себе паспорт или визу. Все воспринимают это как должное - ведь в Сингапуре все работает так. Это не просто удобно, но и гораздо более продуктивно и эффективно» ${ }^{3}$.

Правительство Сингапура уже опубликовало двухмерную онлайн-карту города: она позволяет людям просматривать некоторые данные с систем наблюдения на улицах, отслеживать уровень паводков и искать свободные места на парковках. С помощью этой карты жители могут менять маршруты автобусов, основываясь на местах сбора пассажиров, создавать модели влияния строящихся небоскребов на диаграмму преобладающих ветров и картографировать распространение инфекционных болезней. Сегодня все зарегистрированные в Сингапуре автомобили устанавливают устройства для связи со спутником, которые помогут государству оптимизировать дорожные сборы на основе пройденных километров; также это поможет установить динамическую тарификацию в зависимости от загруженности дорог в течение дня.

Государство обещает размещать различные датчики только там, где они могут принести определенную пользу жителям города. Однако власти обеспокоены проблемами кибербезопасности и признаются, что не все вопросы в этой области решены. По законам Сингапура, использование собранных Smart Nation данных не требует разрешения суда или согласия граждан. Нельзя не отметить, что такой подход недемократичен и нарушает права человека. Более того, если хакерам каким-то образом удастся получить доступ к сети, то огромное количество данных о жизни людей может оказаться под угрозой.

Власти Сингапура признаются, что они еще не в полной мере готовы ответить на все вызовы, связанные с внедрением интеллектуальных технологий. Можно сказать, что развитие технологий здесь намного опережает возможности государства и общества реагировать на их вторжение в общественную и частную жизнь. Среди актуальных задач инициативы Smart Nation в Сингапуре можно назвать:

1) использование всей мощи и потенциала цифровых и интеллектуальных технологий с целью создания новых рабочих мест и возможностей для бизнеса;

2) максимальное удобство проживания в стране;

1 «Умная» ІоТ нация Сингапура. Доступ: http://center2m.ru/news/novosti-iot-rynka/umnaya-iotnatsiya-singapura/ (проверено 21.04.2018).

2 Smart Nation: Singapore. Официальный сайт Управления премьер-министра Сингапура. URL: http:// www.pmo.gov.sg/smartnation (accessed 21.04.2018).

3 «Умная страна» вместо «умного города»: премьер-министр Сингапура о роли технологий в жизни государства. Доступ: https://apparat.cc/world/smart-country/ (проверено 21.04.2018). 
3) увеличение продуктивности экономики за счет более эффективных государственных и бизнес-процессов;

4) создание новых возможностей в эпоху цифровых технологий и трансформация того, как люди живут, работают и играют, чтобы Сингапур оставался выдающимся глобальным городом ${ }^{1}$.

Какие преимущества видит Сингапур в реализации программы Smart Nation? Во-первых, создание «цифровой грамотной популяции» на компактной территории страны. Во-вторых, развитие современной системы образования, ориентированной на технику и науку. В-третьих, формирование высокотехнологичной инфраструктуры страны с высокой скоростью подключения к сети и повсеместным использованием смартфонов. Формирование «умной нации» в «умном городе» осуществляется при максимальном акценте на техническом образовании, развитии человеческого капитала с ориентацией на высокотехнологичное производство и инновации.

Любой гуманитарий, увидев список преимуществ будущей «умной нации», скажет: а как же культура и искусство? Получается, они находятся вне приоритетов «умной нации»?

Действительно, игнорирование гуманитарного развития личности и общества не могло не сказаться на качестве человеческого капитала Сингапура и привело к целому ряду серьезных проблем в развитии государства. Во-первых, упор в системе образования на технических науках привел к сильной технологизации общества и общественного сознания. Сегодня в университетах Сингапура единственным популярным гуманитарным направлением является лингвистика - изучение иностранных языков. Культ техники, точных наук и предпринимательства обернулся тем, что литература и искусство, фундаментальные научные исследования перестали интересовать сингапурцев: за полвека в обществе не сложилось ни одной научной, музыкальной, литературной, художественной или поэтической национальной школы.

В великолепных концертных залах Сингапура играют приглашенные иностранные знаменитости, на подмостках сингапурских театров выступают самые известные театральные коллективы мира. Но блистательные суперсовременные культурные центры острова посещают в основном туристы и бизнесмены из других регионов мира. Сами сингапурцы предпочитают проводить свободное время в многочисленных ресторанах и кафе или занимаются шопингом: здесь существует откровенный культ еды и потребления.

Между тем с точки зрения грамотности Сингапур - одна из самых «продвинутых» стран в мире: уровень грамотности здесь достиг 98\%. При этом, согласно опросам, лишь $40 \%$ населения Сингапура прочитали хотя бы одно литературное произведение за год (в США, к примеру, эта цифра составляет 70\%)ㄹ. Парадокс в том, что из-за сильной технологизации общественного сознания в Сингапуре очень много образованных и умных специалистов, но мало творческих и талантливых людей. Научные открытия, разработка новых перспективных направлений развития науки не увлекают сингапурцев: среди них практически нет выдающихся ученых ни в одной фундаментальной области знаний. И это стало по-настоящему серьезной проблемой: ведь именно интеллектуальный капитал является главным источником богатства и процветания современных

\footnotetext{
1 Реализация инициативы Сингапура «Smart Nation» по состоянию на 2017 год. Доступ: https:// offshorewealth.info/life-abroad/smart-nation-singapore-realization-2017/ (проверено 21.04.2018).

2 Сингапур придумывает, как заставить граждан полюбить литературу. Доступ: http://ibusiness. $\mathrm{ru} / \mathrm{blog} /$ experience/42728?utm_source=\&utm_medium =\&utm_campaign=pochitayte-o-tom--kak-vsingapure-budut-p (проверено 21.04.2018).
} 
государств. Сингапур вынужден покупать таланты - приглашать креативных иностранных специалистов для развития своей страны.

Заметим, что одним из первых антропологическую катастрофу технократического общества предсказал еще Эрих Фромм, назвав человека, погруженного в виртуальное зазеркалье, «моноцеребральным» - человеком одного измерения. Моноцеребральная личность настолько сильно вписана в современную автоматизированную систему, что механизмы также становятся объектом ее нарциссизма: современный человек обожает свои машины не меньше, чем самого себя [Фромм 2008: 467]. Психологи, нейробиологи и психотерапевты сегодня с тревогой пишут о том, что «цифровое слабоумие» в эпоху тотального увлечения человека гаджетами - это медицинский диагноз. Не только в Сингапуре, но и в других развитых странах мира врачи стали отмечать, что все больше людей, увлеченных миром гаджетов, страдают расстройством внимания, когнитивными нарушениями, подавленностью и депрессией, что они не способны к творчеству.

Правительство Сингапура видит эту проблему и пытается как-то исправить ситуацию. Так, современная сингапурская школьная программа по литературе недавно была признана лучшей в мире по версии Program for International Student Assessment. Однако после учебы в школе и университете сингапурцы очень часто забрасывают литературу: опрос 2015 г. показал, что жители острова не могут найти времени для чтения из-за рабочих и семейных обязанностей; более того, большинство из них при этом заявляют, что не интересуются поэзией и прозой. Власти стараются привить интерес граждан к культурному досугу: они, например, активно развивают и модернизируют библиотеки, которые выписывают 36 млн книг в год. На ежегодных распродажах архивов библиотек жителям предлагается 300 тыс. экземпляров книг по символической цене - 1,5 долл. за штуку. Последняя книжная акция 2017 г. предусматривала продажу в общественном транспорте карманных томов с литературной классикой, современной местной литературой и бестселлерами. Запуск программы прошел в рамках настоящего праздника книг, когда в Сингапуре повсюду проходят выставки, встречи с авторами, семинары. В дальнейшем планируется, что подобные акции будут частью большой пятилетней программы под названием «Национальное движение читателей», которая призвана повысить уровень популярности литературы в стране ${ }^{1}$.

Удастся ли правительству восстановить творческий потенциал «умной нации»? Это интересный вопрос, точный ответ на который мы получим через несколько десятков лет. Но уже сегодня очевидно: очень опасно экспериментировать с системой образования, искусственно делая уклон в технические науки, отодвигая искусство и литературу на второй план. Технократия убивает творческий дух: ведь креативный потенциал личности наиболее полно раскрывается в гармоничной, богатой культурными впечатлениями среде. Американский писатель Уильям Гибсон написал весьма любопытную статью о культуре Сингапура под названием «Диснейленд со смертной казнью» 2 , в которой раскритиковал «мягкий авторитаризм» страны. Сингапурское правительство запретило журнал Wired, где была опубликована статья, но в интеллектуальных кругах название «Диснейленд со смертной казнью» стало крылатым выражением. Интересно, что сегодня статья Гибсона включена в программу Национального университета Сингапура по теме «Развитие Сингапура» учебного курса «Письмо и кри-

\footnotetext{
1 Там же.

2 Gibson William. Disneyland with the Death Penalty. - Wired (Condé Nast Publications). URL: https:// www.wired.com/1993/04/gibson-2/ (accessed 21.04.2018).
} 
тическое мышление». Это свидетельствует о том, что сингапурцы следят за критикой и стремятся повысить общественную культуру.

В своей яркой сатирической статье Гибсон справедливо отметил, что Сингапур представляет собой опыт построения государства, управляемого, как крупная корпорация: «Если бы в IВМ захотели обзавестись своим государством, это государство имело бы много общего с Сингапуром. Тут и обязательное ношение белых рубашек, и полное отсутствие чувства юмора, и конформизм во главе угла, а творческая мысль в большом дефиците. Прошлое здесь растворилось без остатка. В Сингапуре нет никакой расслабленности: там все ориентировано на экономику. Представьте себе азиатскую версию Цюриха, который расположился у подножия Малайзии. Богатый мирок, среди жителей которого чувствуешь себя так же хорошо, как в Диснейленде. В Диснейленде со смертной казнью» 1 .

Действительно, в Сингапуре смертная казнь предусмотрена за значительное число тяжких преступлений: убийство, государственную измену, шпионаж, торговлю наркотиками. По заявлениям властей, во многом из-за существования смертной казни уровень преступности в государстве с населением 5 млн чел. является одним из самых низких в мире. Однако негибкая драконовская юридическая система страны не раз подвергалась критике зарубежных общественных деятелей.

Сокрушительной критике зарубежных общественных деятелей подвергается также жесткая цензура Сингапура (так называемый отдел нежелательной пропаганды): многие обратили внимание на то, что местные газеты, в т.ч. таблоид New Paper, по существу, являются государственными органами, инструментами распространения только желательных новостей. Как язвительно пишет тот же Гибсон, «эта непрерывная хвала на службе порядка, здоровья и процветания сингапурского пути быстро вызывает ощущение оруэлловского страха, что Большой брат преследует вас сзади со счастливым лицом... Разумеется, в Сингапуре можно жить, получая информацию об окружающем мире, но доступ к определенным сведениям будет либо сильно сужен, либо отключен» ${ }^{2}$. Все это не может не возмущать представителей творческой интеллигенции, посещающей «умный» остров.

Действительно, современному Сингапуру остро не хватает духа творчества, полета мысли, фантазии, креативности и аутентичности. «Умная нация» в Сингапуре во многом развивается сегодня за счет привлечения иностранных специалистов и ученых со всего мира. Наверное, это та цена, которую страна заплатила за слишком быстрые темпы индустриализации в ущерб развитию духовной культуры общества. Поэтому, отмечая явные успехи этого островного государства, нельзя умолчать и о его серьезных просчетах: здесь со всей силой проявилось известное библейское пророчество - можно приобрести весь мир и потерять свою душу.

В самом деле, обозревая блистательные перспективы амбициозного сингапурского проекта «умной нации», сложно удержаться от вопроса: можно ли назвать действительно «умной» нацию, которая явно утрачивает креативность и гуманизм на пути достижения материального процветания и комфорта?

Сегодня, когда Россия ставит перед собой задачи развития «цифровой экономики» и формирования первых «умных городов» в нашей стране, особенно важно обратить внимание на проблемы и вызовы модели супертехнологического общества, которое уже во многом сформировалось в Сингапуре. Это

\footnotetext{
1 Ibid.

2 Ibid.
} 
позволит нам не повторять роковых ошибок и заблуждений при разработке национальной модели «умного города» и «цифровой экономики».

\title{
Список литературы
}

Глейзер Э.Л. 2015. Триумф города: Как наше величайшее изобретение делает нас богаче, умнее, экологичнее, здоровее и счастливее. М.: Изд-во Института Гайдара. $432 \mathrm{c}$.

Фромм Э. 2008. Анатомия человеческой деструктивности (пер. с англ. Э.М. Телятникова, Т.В. Панфилова). М.: АСТ. 635 с.

VASILENKO Irina Alekseevna, Dr.Sci. (Pol.Sci.), Professor of the Chair of Russian Politics, Faculty of Political Science, Lomonosov Moscow State University (bld. 4 «Shuvalovskij», 27 Lomonosovsky Ave, Moscow, Russia, 119991; vasilenko. irina@mail.ru)

\section{«SINGAPORE MIRACLE» IN THE FOCUS OF POLITICAL ANALYSIS: THE TEMPTATION AND DISAPPOINTMENT IN ASIAN HI-TECH UTOPIA}

\begin{abstract}
The article analyzes the ambitious project of Singapore aimed at building a smart nation that uses intelligent management and smart technologies in all spheres of public life. The rapid development of smart technologies in Singapore marked not only the technological peaks of the future smart nation, promising material abundance and comfort, but also the no less dangerous humanitarian and anthropological risks of this project, reflected in the loss of creativity and humanity of society. Therefore, the rethinking of the unique experience of the Singapore project will allow not only to understand better its achievements, but also to see serious problems and dangerous delusions on the way to the formation of a smart nation. Keywords: Singapore, smart nation, smart city, smart technologies, humanitarian risks, anthropological risks
\end{abstract}

